\title{
Saberes históricos diante da avaliação do ensino: notas sobre os conteúdos de história nas provas do Exame Nacional do Ensino Médio - ENEM ${ }^{1}$ \\ Luis Fernando Cerri Universidade Estadual de Ponta Grossa — UEPG (PR)
}

\section{RESUMO}

Este texto constitui um apanhado sobre o contexto em que os Parâmetros Curriculares Nacionais vêm a público, e procura traçar paralelos entre alguns elementos desse contexto e o conteúdo que tais documentos propõem, como também entre os problemas e as possibilidades por eles trazidas ao trabalho do professor: recompor os conteúdos, contribuir para a formação do aluno, prepará-lo para o Exame Nacional do Ensino Médio e para os concursos vestibulares. O objetivo é demonstrar que o ENEM, entre outras práticas avaliativas criadas no governo Fernando Henrique Cardoso (1995-2002), constitui um fator de organização do currículo do Ensino Médio, conjuntamente com (e por vezes apesar deles) os documentos tradicionalmente reconhecidos como currículos, e portanto constitui um fator importante da escolha e dosagem de saberes históricos operados junto à faixa crescente da população brasileira que conclui esse nível educacional.

Palavras-chave: Ensino de História; Avaliação; Políticas Públicas.

\section{ABSTRACT}

This paper performs a summary about the context of publication of the National Curricula Standards, and attempts to draw parallels between some elements of the context and the affiliations of these documents to the contents that they propose, and the problems and possibilities that they bring to the teacher's work (recompose the contents, contribute to the pupil's development, preparing them to the National Evaluation of the Secondary Level — ENEM and admissionary exams to the superior level). The objective is to demonstrate that the ENEM, among other evaluative practices created at Fernando Henrique Cardoso period (1995-2002), plays an organizational paper to the curriculum of secondary education, and therefore makes an important factor at the choosing and dosing of historical knowledge operated next to the growing group of the Brazilian population, who completes this educational level.

Keywords: History teaching; Evaluation; Public policies. 
Muito se discute sobre os currículos de História para a Escola Básica, e com justiça. Os currículos são elementos centrais na atividade educativa e expressam significativamente as noções, concepções, conceitos e preconceitos sobre a sociedade, a ciência, a educação e o ser humano, no momento em que são elaborados. Os estudos nessa área, todavia, são claros em apontar que a atividade educativa desenvolvida na sala de aula é uma realidade que o currículo (entendido como a orientação da atividade dos professores cristalizada num documento ou conjunto de documentos) influencia, mas não governa. Entre o currículo prescrito e o aprendizado do aluno interpõem-se fenômenos (como o currículo oculto e os condicionamentos específicos de cada escola e de cada sala) que produzem o currículo realizado, distinto daquele se prescreveu. Um dos fatores que condiciona a efetivação do currículo é a avaliação externa à escola. Nesse sentido, é de longa data que os exames vestibulares vêm se comportando como o principal organizador do currículo do Ensino Médio, e nesse campo, aos poucos o Exame Nacional do Ensino Médio - ENEM vem ganhando um espaço expressivo.

O objetivo deste texto é desenvolver uma reflexão despretensiosa em torno das políticas públicas para o Ensino Médio, especialmente o ENEM e os Parâmetros Curriculares Nacionais para o Ensino Médio - PCNEM, buscando tecer algumas considerações sobre as relações entre o currículo e a avaliação, no que tange aos conteúdos históricos considerados pelo Estado como necessários ao estudante que passou pela Educação Básica obrigatória.

\section{CON-TeXTOS}

Esta parte ocidental do mundo da qual somos periferia revolveu-se durante todo o século passado temendo o totalitarismo e as ditaduras, sonhando e ansiando pela liberdade e pela democracia. Expressão dramática dessa apreensão é o livro 1984, do escritor inglês George Orwell, em que o autor traça - impressionado pelo nazismo e pelo stalinismo - uma sociedade negativamente utópica, em que tudo e todos são controlados por um poder central ao mesmo tempo familiar e desconhecido, presente em todos os lugares e ao mesmo tempo de entranhas obscuras.

Nós, que chegamos ao século XXI, podemos avaliar que Orwell errou e acertou. Nem o socialismo stalinista nem o nazismo vingaram, mas o totalitarismo vem sendo construído sob o capitalismo liberal, nas grandes ações da globalização e nos pequenos poderes locais e interpessoais. Na velha In- 
glaterra, por exemplo, câmeras escondidas vão vigiando a tudo e a todos, e por estas plagas a moda vai pegando... Testes revelam quem usa e quem deixa de usar drogas, e um grande programa de computador dos órgãos de inteligência norte-americanos monitora nossas navegações pela Internet. Mas, de fato, os vaqueiros que tangem a humanidade encontram sua força no medo das pessoas, medo de perder as pequenas compensações da submissão. Entretanto, não existe natureza humana fechada e resolvida: temos potencialidade para a escravidão ou para a liberdade. 1984 está chegando ou já passou?

Essas considerações servem para lembrar sempre - nunca é demais que as representações que os regimes e seus poderes fazem sobre si mesmos (ou, num olhar mais benévolo, aquilo que querem ser) geralmente estão descoladas do que efetivamente são, em termos de resultados observáveis. Não seria necessário lembrar isso se a fala oficial não acabasse sendo tomada acriticamente como expressão da realidade, como instrumento de classificação e caracterização da vida política e social. Essas considerações dão o tom do brevíssimo panorama que passaremos a traçar sobre as recentes reformas e os atuais desafios do Ensino Médio e, nele, do conhecimento histórico, diante das práticas de avaliação promovidas pelo Governo Federal, para iniciar, portanto, colocando em dúvida os elementos que no discurso oficial são postos como autonomia, flexibilidade e crítica. Por exemplo, o hiato entre o que é chamado de flexibilidade e autonomia em documentos como a LDB 9394/96 e os Parâmetros e Diretrizes Curriculares Nacionais, principalmente, e o contexto impositivo no qual eles se apresentam ao professor, entre suas falas sobre cidadania e a concepção de cidadania que as embasa, bem como embasa as atitudes do poder que esses documentos significaram para o professor e para a escola.

O primeiro aspecto a destacar é a internacionalidade dessas leis que se autodenominam nacionais, uma vez que respondem prioritariamente a imperativos de organismos internacionais, bem como a orientações assumidas como nacionais por tecnocratas formados e treinados sob a ótica primeiromundista sobre os nossos problemas. A “inspiração” em recomendações de órgãos como FMI, Banco Mundial e Banco Interamericano de Desenvolvimento acarreta marcas profundas nesses programas, entre as quais podemos destacar o economismo, o determinismo tecnológico, a racionalidade técnica e o condicionamento da cidadania a ser formada.

A professora Maria Sylvia Bueno identifica nesses documentos aquilo que chama de "idéias-força", ou seja, teses que ganham força de dogma e que já vêm com embalagem inviolável nos pacotes curriculares para o ensino, afe- 
tando sua constituição principalmente no que se refere às Ciências Humanas. As idéias-força presentes na legislação federal desde o início do mandato do presidente Fernando Henrique Cardoso, pelo menos, são "a suprema responsabilidade pelas transformações sociais delegada à educação", "o conhecimento humano rebaixado a recurso estratégico do desenvolvimento, confundido com informação", "a visão messiânica da tecnologia", "o raciocínio economicista/empresarial subjacente aos modelos educativos" e "um conceito de qualidade vinculado à perspectiva empresarial de eficiência, eficácia e política de resultados", ${ }^{2}$ entre outras. Essas idéias-força vão interferir decisivamente na forma pela qual essa legislação se relaciona com o professor e também nos conteúdos e seus critérios de seleção. Marcos Soares indica que a tentativa de síntese entre humanismo e tecnologia é o fundamento articular dessa proposta curricular. ${ }^{3}$ Sobre o professor, inicialmente, essas políticas acentuaram uma postura, nas instâncias burocráticas, de desconfiança, desprestígio e disposição de vigilância e direcionamento dele e de seu trabalho, naquilo que Giroux chamará de "programas a prova de professor", ${ }^{4}$ ou seja, pensados para serem implementados apesar do corpo docente.

Em primeiro lugar, é preciso esboçar a trajetória dessas leis. Elas estão enraizadas no programa de governo do presidente Fernando Henrique Cardoso, desenvolvem-se no Planejamento Político-Estratégico do MEC de 1995 e em leis que foram sendo aprovadas no espírito da nova LDB antes mesmo que ela fosse promulgada (como todos sabem, numa manobra parlamentar que deixou para trás anos de participação e discussão acumuladas). Ou seja, um projeto de partes integradas legitimado a posteriori, no qual a discussão pública com os destinatários ocorre apenas como recurso cosmético, para dar um ar de democracia à coisa toda. Muitos participaram de um processo de consultas no momento de elaboração dos PCN, mas o processo foi assistemático e não dialógico, os consultados não tiveram poder de decisão. Dá uma tese investigar em que medida essa participação afetou a essência do documento, que já estava posta anteriormente pelo MEC; minha hipótese é que — novamente estamos apenas diante de um ritual de legitimação de uma diretriz já definida em seu âmago, que negocia apenas o que é acessório. A começar pela própria necessidade ou não de fazer essas mudanças da forma e no âmbito em que foram feitas. Infelizmente, essa prática encarnou-se em dirigentes e técnicos, de tal modo que tende a ser reproduzida no atual governo do presidente Luiz Inácio Lula da Silva, a exemplo da Reforma Previdenciária.

Todo esse quadro coloca para o professor uma situação de "desconfirmação positiva”, termos que José Terrero ${ }^{5}$ usa quando se refere à relação entre 
a população empobrecida e a mídia, que louva o pobre no verbo mas despreza-o na atitude monológica. O professor é submetido, na recepção desses documentos, a uma comunicação que no aspecto verbal é democrática, autonomizadora, crítica e flexível, mas no ato de impor-se como "verdade pedagógica" desconfirma o docente, reduzindo-o a mero executor e ignorante do seu próprio ofício. Nas palavras de Henry Giroux,

os reformadores educacionais têm respondido às crises na educação pública principalmente oferecendo soluções que ignoram o papel dos professores na preparação dos estudantes para se tornarem cidadãos críticos e ativos, ou sugerem reformas que ignoram a inteligência, julgamento e experiência que os professores poderiam trazer para resolver esses problemas. ${ }^{6}$

É evidente que esse processo de marginalização e exclusão do professor não é exclusividade brasileira e nem algo inaugurado pelas atuais políticas públicas para a educação. Tanto que existe a expressão em inglês "teacher burnout", que poderia ser traduzida elegantemente como "mal-estar docente", ou, como na fala cotidiana, "queimação de professores", conforme o gosto do freguês. Essa síndrome, que leva ao afastamento do profissional, tem entre suas causas um profundo desânimo diante da profissão, que por sua vez tem como principais fatores a ausência de autonomia, a sensação de impotência e a insatisfação crônica em relação aos resultados do trabalho. Apenas recentemente os gestores públicos estão começando a dar atenção às estatísticas de mal-estar docente. O que se constata é que, apesar da verbalização em contrário, não há inovação no que se refere ao papel do professor, que no final das contas é quem carregará toda a responsabilidade de fazer isso tudo funcionar na sala de aula, sem ter opinado sobre como fazê-lo. Resta perguntar: como o excluído pode incluir? ${ }^{7}$

Para não nos estendermos demasiadamente nesta contextualização, trataremos mais apenas do aspecto do "determinismo tecnológico"/"racionalidade técnica” nessas orientações curriculares. Os PCN só podem ser entendidos dentro do contexto no qual o "discurso competente" sobre a educação não está mais nas falas dos educadores, mas no dos economistas, pelo menos para o governo FHC, para seus financiadores e seus teóricos. Confira-se a formação acadêmica do ex-Ministro da Educação. Neste triunfal retorno da tecnocracia, o que chama a atenção não é mais a desconfirmação positiva dos professores, nossa velha conhecida, mas a subordinação das diretrizes para a Educação ao discurso financeiro/econômico/empresarial. Nessa perspectiva 
de racionalidade técnica, quem sabe determina, quem não sabe executa. Daí a considerar o professor como "algoz incompetente" e foco da mudança educacional é um passo; com esse passo vem também o processo de subjugação da autoridade do professor, num processo de planejamento que é inócuo pois não é capaz de olhar o "chão da escola". Não se propõe a entendê-la e ao professor, mas a normatizar. A racionalidade técnica opõe-se à práxis reflexiva, é incapaz de ser empática em relação ao professor, e, arrisco-me a dizer, incapaz de resolver a crise da educação porque jamais poderá conseguir o engajamento voluntário, consciente do professor, por não ser capaz de mobilizar o desejo da categoria. E não se pode negar a margem de autonomia que o professor constrói, em processos de resistência que vão desde a crítica aberta até a "negligência" com o processo educativo, passando pelos mais variados graus de fingimento, pelos quais consegue parecer, diante do olhar burocrático, que está a fazer o que lhe determinam, quando efetivamente está a fazer o que entende como correto.

\section{Conteúdos de História no Ensino Médio}

A primeira coisa que causa estranhamento a quem lê os PCNEM é a utilização da expressão "Ciências Humanas e suas Tecnologias”. O estranhamento do leitor ganha uma resposta: trata-se de uma perspectiva que procura uma síntese nova entre o ideal formativo de cidadãos, das humanidades, e a tecnologia que preenche os horizontes contemporâneos. Por que o ensino de humanidades no século XIX não precisava referir-se à tecnologia, que naquele momento também tinha um papel revolucionário, guardadas as devidas proporções? Talvez porque hoje a tecnologia tenha inundado o cotidiano envolvendo tudo, ou talvez porque a "tecnologia" seja um objeto (ou um sujeito) de reverência, por parecer um fenômeno impessoal que nos carrega a todos como uma tromba d'água! "Tecnologia” parece, então, uma dessas coisas sobre as quais não temos nenhum controle enquanto espécie, como o fato de chover sempre na hora em que estamos indo ou vindo de algum lugar, como o fato de fazer um calor infernal ou um frio excessivo. Determinismo tecnológico. Tecnologia, mercado, representação política, são essas coisas para as quais temos que preparar e adaptar os alunos, para que possam encontrar um lugar em meio a isso tudo e não sejam excluídos. Daí pode-se depreender parte do conceito de cidadania que compõe o conteúdo dos PCN, porque "formar o cidadão" é uma missão da História desde que ela se instituiu enquanto 
disciplina, e o problema começa quando queremos saber o que se está entendendo por cidadania.

Uma característica geral do conteúdo nos PCNEM é que desaparecem as antigas listagens de conteúdos fatuais mínimos obrigatórios, para dar espaço a orientações que têm por função estruturar os conteúdos que pretensamente o professor vai escolher com liberdade. Avança no sentido de que os conteúdos são finalmente institucionalizados como meio e não como fim, mas devemos examinar mais de perto essa flexibilidade que nos é oferecida, procurando nas noções jurídicas de lei e de norma o âmbito dessa liberdade.

As análises críticas de Michel Foucault fazem duvidar se as regras estabelecidas de fato correspondem ao direito, na medida em que põem em evidência um outro modelo de disciplina, que se pode chamar de militar, não envolvendo a coerção direta nem formas externas de obediência, garantindose através de um controle do tempo, dos trajetos e dos gestos das pessoas submetidas (controle dos corpos em movimento). Pensar e planejar são atribuições de quem tem o poder; obedecer rápida e eficientemente são as do que se submete, ainda que essa obediência tenha toda a cara de uma seleção própria dos conteúdos. Os PCNEM são positivos, normativos. Não surgem como comportamento jurídico fundado sobre a lógica da lei, que é negativa, estabelecendo o permitido e o proibido, mas respeitando a individualidade na medida em que permite tudo o que não proíbe. Os PCNEM propõem um comportamento disciplinar, fundado sobre a lógica da norma, que é positiva, ao determinarem um padrão de comportamento médio ao qual todos devem adequar-se, com o que substituem a espontaneidade e a iniciativa individuais, com base no discurso científico. Traçam-se objetivos para a História e as humanidades no Ensino Médio, os caminhos teóricos e metodológicos também são traçados e travados. A mobilidade do professor é posta apenas a partir daí, na hora de selecionar o que ensinar, e os objetivos e os critérios de seleção já estão dados.

Ao mesmo tempo em que se estabelece uma pretensa igualdade em que todos aparecem igualmente como definidores de conteúdos, essa igualdade é corroída pela existência de uma hierarquia que reduz a liberdade de quem está na base. A crítica de Foucault para o contrato social, que vale para o que estamos analisando, é que esse contrato supõe igualdade formal entre todos, mas a disciplina corrói essa igualdade na medida em que estabelece pessoas que organizam a disciplina e as normas e pessoas que se submetem a elas. ${ }^{8}$

Outro dado interessante dos PCNEM é que eles assumem uma incômoda didática para o professor, explicando-lhe detidamente o que é, por exem- 
plo, o tempo histórico. Admitamos que existem professores que não conhecem esse assunto; mas assumir tal postura no texto que equivale a um currículo nacional dá-nos um indício significativo do perfil do professor que é imaginado pelo MEC, de qual é a imagem de professor que articula os PCNEM.

Vamos agora listar algumas das diretrizes para a seleção dos conteúdos de História segundo os PCNEM, com um duplo objetivo: comentá-las criticamente e possibilitar conferir a sua presença nos conteúdos que são exigidos pelo ENEM.

\section{Estruturação do conteúdo por temas articulados em torno da constru-} ção de conceitos. O documento assume a impossibilidade da tarefa que é tentada pelos defensores da História Integrada, de abordar "toda a História”, impossibilidade aliás já apontada há muito tempo pelos professores de História do Ensino Médio, dispondo de poucas horas semanais por turma. Os PCNEM propõem dar uma ordenação diferente da cronológica a um ensino que já é constituído de uma seleção de conteúdos, por razões pragmáticas.

Privilegiamento dos conteúdos de História nacional, conectados à História Geral por relações de contexto. Os PCNEM, bem como os PCN para o Ensino Fundamental, não escondem sua intenção nacionalizadora, de formação de identidade comum aos brasileiros, postura que é inerente a uma política pública que retoma, após quase 70 anos, o papel centralizador do Governo Federal na legislação sobre os currículos, e que nacionaliza a avaliação da sua aplicação. A nacionalização não pode ser definida a priori como positiva ou negativa, porque essa avaliação depende dos valores do sujeito bem como das múltiplas variáveis do contexto no qual ele se efetiva. Mas essa advertência também serve para identificarmos a faca de dois gumes que se coloca diante de nós. A nacionalização via educação pode tanto preparar as consciências para guerras por mercado quanto mobilizar populações por sua independência. Resta perguntar para que é que seguiremos centrados numa estruturação dos conteúdos com base na idéia de nação, a quem isso serve; trata-se de mais um dos consensos decretados sem discussão e que tende a ser tomado como dado da realidade e não como opção de uma política educativa e cultural do atual governo.

Padrão interdisciplinar, por exemplo entendendo o desenvolvimento histórico em articulação com a ocupação do espaço. Embora existam conteúdos e objetivos específicos da História, os PCNEM apontam para o ensino integrado das Humanidades. Se por um lado subsiste uma postura das mais defendidas em termos de ensino-aprendizagem, por outro é preciso tomar cuidado para que a especificidade da História não se perca, até porque o tex- 
to oficial não aponta para a fragmentação desses conteúdos em disciplinas, mas a sua integração em práticas educativas unificadas.

Produção de "condutas de indagação". É interessante fazer um exercício de imaginação: o que o documento, no contexto da política educacional, compreende por condutas de indagação, espírito de investigação e expressões assemelhadas? Qual a profundidade dessa atitude questionadora a ser implementada? Sim, porque existem diferentes níveis de indagação, como existem diferentes níveis de crítica. Por exemplo: "o Brasil não tem jeito porque os políticos são ladrões", é uma frase que, independentemente da superficialidade, é uma frase crítica. É esse tipo/nível de crítica que a indagação produzirá, ou é outro? Podemos ficar na dúvida, porque a implantação dos PCN depende da aceitação de pressupostos que não são discutidos, como já dissemos, depende de uma conduta do professor oposta à indagação dos princípios de sua prática, princípios filosóficos e políticos que se cristalizam no currículo.

Compreensão das tecnologias associadas à área. A tecnologia é um fetiche dos PCNEM de uma forma geral, um objeto de fascínio que é assumido como sujeito histórico, sem que haja uma recuperação do seu estabelecimento como chave explicativa da contemporaneidade, e isso constitui mais um dos dogmas fundantes da reforma curricular cuja implantação estamos discutindo. Esse fetiche obriga à genuflexão verbal da expressão "Ciências Humanas e suas tecnologias", fazendo que esse campo do conhecimento seja obrigado a conviver com um termo que historicamente não tem servido para expressar o produto do seu trabalho. Pode-se interpretar que essa terminologia expressa a atribuição de uma função utilitária imediata para as Humanidades, pois predominam assuntos relativos a resultados da ação das Ciências Humanas para melhoria do mundo do trabalho (gestão dos indivíduos e dos grupos, planejamento, obtenção e organização de informações, e assim por diante), enquanto escasseiam propostas para a discussão política e social do mundo do trabalho em si, se ele interessa ou não como está para o sujeito que o estuda. Adaptar-se para sobreviver, em vez de compreender para transformar. O "fim da História" orienta o ensino da História e das Humanidades para o texto dos PCNEM, e nesse sentido é interessante perguntar até que ponto os conteúdos de História são realmente históricos, no sentido de permitirem pensar o significado dos fatos a partir do inédito e da criação, em vez de fixarem a origem e o significado dos fatos, oferecendo signos fixos e constantes que neutralizam toda contradição possível entre o que está dado e o que pode surgir historicamente, ditando então normas fechadas para a ação e o progresso. ${ }^{9}$ Não que as Ciências Humanas sejam diletantes, mas sua função pri- 
mordial é pensar e partilhar o ato de pensar o homem em relação ao mundo, o que não se encaixa imediatamente com a produção de bens passíveis de um emprego econômico. Diante disso tudo, para selecionar seu conteúdo, o professor precisa estar atento à subjetivização da tecnologia, a sua assunção como causa, substituindo a ação de pessoas, grupos, classes sociais, regimes. Porém, se a intenção é fortalecer o papel das Humanidades diante das disciplinas referenciadas nas ciências propriamente produtoras de tecnologias, então o que ocorre é um duplo equívoco: de imaginar, ratificando o senso comum, as disciplinas referenciadas nas Ciências Humanas como hierarquicamente inferiores, e de imaginar que dando a elas o status de produtoras de tecnologia, reforçam-se em termos de importância no currículo e na prática escolar.

Competências como metas às quais a seleção de conteúdos e sua didatização deverão estar atentas (representação e comunicação, investigação e compreensão, contextualização sócio-cultural). Essa disposição poderia fazer-nos imaginar alguma semelhança com as reformas curriculares de História marcadas pelo liberalismo da velha Inglaterra em meados da década de 1980, em que, para o ensino secundário foram definidas metas em termos cognitivos e de habilidades, que permitiam ao professor utilizar qualquer programa, metodologia ou conteúdo, desde que essas metas fossem atingidas. ${ }^{10}$ Os PCN, entretanto, como já afirmamos, são bem mais prescritivos. Mas é importante registrar o posicionamento de que as competências não são construídas na escola, mas sim nas situações reais de vida e trabalho, uma vez que a "pedagogia das competências" tem dificuldades em compreender as especificidades do conhecimento tácito em relação ao conhecimento formal e organizado, da escola. ${ }^{11}$

\section{CONHECIMENTO HISTÓRICO E O ENEM}

Numa visão geral, as seis edições do ENEM até $2003{ }^{12}$ trazem setenta questões que podem ser consideradas dentro do campo do conhecimento histórico, ainda que não se possa afirmar que existam questões estritamente voltadas para a disciplina; pelo contrário, as questões articulam conhecimento histórico com elementos gerais das "humanidades", de acordo com a proposta de áreas presente nos PCNEM. Para chegar a esse número, consideramos apenas as questões nas quais o conhecimento histórico — informações ou conceitos - é requerido indispensável ou acessoriamente para a resolução do enunciado. Essa distinção precisa ser feita porque muitas das questões envolvem temas históricos (o que pode ser interpretado como um esforço no 
sentido de praticar a interdisciplinaridade enunciada nos PCNEM), mas apenas na condição de pano de fundo, ou seja, seus enunciados não demandam conhecimento histórico para a resolução do que se pede, remetendo na verdade a conhecimentos de outras disciplinas, como a Matemática ou a Geografia. Além disso, o conhecimento histórico em uma grande parte dos casos parece constituir apenas um pretexto para a avaliação de capacidades cognitivas (as "competência e habilidades"): na medida em que o próprio enunciado das questões fornece informações, idéias e conceitos, com algum conhecimento geral e habilidade de interpretação de texto e estabelecimento de relações, entre outras, é possível responder às questões. Saber história acaba aparecendo como elemento facilitador na maior parte das questões, mas não como elemento decisivo. Exatamente oposta ao outro tipo de avaliação, que se baseia na memorização de informações. Vejamos o seguinte exemplo, extraído da prova de 1999:

Considere os textos abaixo:

(...) de modo particular, quero encorajar os crentes empenhados no campo da filosofia para que iluminem os diversos âmbitos da atividade humana, graças ao exercício de uma razão que se torna mais segura e perspicaz com o apoio que recebe da fé.

(Papa João Paulo II. Carta Encíclica Fides et Ratio aos bispos da Igreja Católica sobre as relações entre fé e razão, 1998)

As verdades da razão natural não contradizem as verdades da fé cristã.

(São Tomás de Aquino, pensador medieval)

Refletindo sobre os textos, pode-se concluir que

(A) a encíclica papal está em contradição com o pensamento de São Tomás de Aquino, refletindo a diferença de épocas.

(B) a encíclica papal procura complementar São Tomás de Aquino, pois este colocava a razão natural acima da fé.

(C) a Igreja medieval valorizava a razão mais do que a encíclica de João Paulo II.

(D) o pensamento teológico teve sua importância na Idade Média, mas, em nossos dias, não tem relação com o pensamento filosófico.

(E) tanto a encíclica papal como a frase de São Tomás de Aquino procuram conciliar os pensamentos sobre fé e razão. 
Percebe-se que não é necessário ao leitor conhecer o pensamento de São Tomás de Aquino, uma vez que a atividade cognitiva solicitada é a correta interpretação dos textos e a comparação entre os mesmos.

Das setenta questões identificadas, a composição por períodos históricos abordados é aproximadamente a seguinte:

1 questão refere-se especificamente à História Antiga e duas referem-se especificamente ao período Medieval;

8 questões podem ser encontradas versando sobre a História Moderna e 24 sobre História Contemporânea;

5 questões abordam o período da América Portuguesa e outras cinco abordam o Brasil Imperial, enquanto 24 abordam o Brasil Republicano, com uma larga vantagem para o período após 1950. Deve-se considerar que existem questões que envolvem mais que um período histórico, nove das quais pedem comparações sobre conteúdos de dois ou mais períodos;

4 questões não se referem a nenhum período em especial, tratando de questões teóricas: duas sobre relatividade cultural, uma sobre conhecimento (científico/religioso) e uma quarta sobre periodização.

Nesse quadro, podemos observar a realização de um dos princípios dos PCNEM, que consiste em privilegiar períodos e problemas referidos mais diretamente ao presente. Se por um lado essa postura valoriza, ou melhor, estabelece como imprescindível o concurso da História para a compreensão do mundo atual, por outro ela coloca em xeque a própria motivação de trabalhar com a História e fazer referência ao passado da experiência humana, uma vez que, quanto mais distante no tempo, menos o período é considerado significativo para a compreensão da contemporaneidade. Essa lógica des-historiciza a reflexão sobre a relação entre o passado e o presente, e está ligada a uma postura que pode ser lida como utilitarista: na medida em que o currículo, na visão neoliberal que o embasou, é destinado a capacitar os jovens para que se adaptem ao mundo globalizado, de que servem conhecimentos sobre um passado distante? Esse conhecimento erudito, argumenta-se, é resquício de uma era em que a educação destinava-se às elites ociosas, e não à formação das classes trabalhadoras; perigoso, esse raciocínio pode ser continuado da seguinte maneira: se o objetivo da educação é formar trabalhadores, por que ensinar-lhes algo além daquilo que precisarão para entender seu ofício, seja ele de - dizia Gramsci ao referir-se ao ensino das línguas clássi- 
cas — “camareiro, intérprete, correspondente comercial"? Para que ele precisará de conhecimento histórico?

Não se trata de retomar a defesa da prioridade dos estudos clássicos, mas de questionar a compreensão de utilidade do conhecimento histórico que os PCNEM apresentam e que o exame das questões do ENEM confirma. Equivocadamente, o conhecimento parece tanto mais útil e concreto para o aluno quanto mais próximo ele estiver do presente, o que é um erro, uma vez que a "concretude" de um saber não passa necessariamente pela sua proximidade espacial ou temporal, sobretudo num mundo ocupado pela comunicação de massa. Pelo contrário, a "concretude" ou a "utilidade" de um conhecimento histórico estão muito mais dadas pela sua possibilidade de dialogar com o presente e escavar seus significados, compondo um conjunto significativo. $\mathrm{O}$ pequeno número de questões comparativas entre períodos é um outro indicativo desse problema.

Pedro Paulo Funari, ao contrário, demonstra que, para além de uma formação cultural elitista, o conhecimento da História Antiga, se aprofundado e criterioso, permite perceber tanto as raízes de fenômenos da contemporaneidade quanto a heterogeneidade de sujeitos e visões de mundo que podem alimentar as discussões sobre conflitos, opressão e a questão do poder na construção da narrativa histórica. ${ }^{13}$

Retomemos, agora, uma questão já delineada: qual a relação entre os conteúdos históricos, as habilidades referentes ao método e ao pensamento histórico e os quesitos exigidos na resolução das questões? Em outros termos: se argumentamos anteriormente que a avaliação na terminalidade do ensino médio - seja o exame vestibular, seja o ENEM — tem força de currículo, devemos perguntar como se constitui essa influência, no caso do ENEM: que temas impõem-se como conteúdos para o aluno que será um virtual candidato ao exame? Quais as características do ensino de História que o ENEM estimula?

Vejamos a seguinte questão, do ENEM de 1998:

A figura de Getúlio Vargas, como personagem histórica, é bastante polêmica, devido à complexidade e à magnitude de suas ações como presidente do Brasil durante um longo período de quinze anos (1930-1945). Foram anos de grandes e importantes mudanças para o país e para o mundo. Pode-se perceber o destaque dado a Getúlio Vargas pelo simples fato de este período ser conhecido no Brasil como a "Era Vargas".

Entretanto, Vargas não é visto de forma favorável por todos. Se muitos o con- 
sideram como um fervoroso nacionalista, um progressista ativo e o "Pai dos Pobres", existem outros tantos que o definem como ditador oportunista, um intervencionista e amigo das elites.

Considerando as colocações acima, responda à questão seguinte, assinalando a alternativa correta. Provavelmente você percebeu que as duas opiniões sobre Vargas são opostas, defendendo valores praticamente antagônicos. As diferentes interpretações do papel de uma personalidade histórica podem ser explicadas, conforme uma das opções abaixo. Assinale-a:

(A) Um dos grupos está totalmente errado, uma vez que a permanência no poder depende de idéias coerentes e de uma política contínua.

(B) O grupo que acusa Vargas de ser ditador está totalmente errado. Ele nunca teve uma orientação ideológica favorável aos regimes politicamente fechados e só tomou medidas duras forçado pelas circunstâncias.

(C) Os dois grupos estão certos. Cada um mostra Vargas da forma que serve melhor aos seus interesses, pois ele foi um governante apático e fraco um verdadeiro marionete nas mãos das elites da época.

(D) O grupo que defende Vargas como um autêntico nacionalista está totalmente enganado. Poucas medidas nacionalizantes foram tomadas para iludir os brasileiros, devido à política populista do varguismo, e ele fazia tudo para agradar aos grupos estrangeiros.

(E) Os dois grupos estão errados, por assumirem características parciais e, às vezes conjunturais, como sendo posturas definitivas e absolutas.

A resposta correta no gabarito é a (E). À parte do problema que consiste em colocar a questão em termos de certo ou errado, cabe refletir sobre o que ocorre com o aluno se o seu professor, nos recortes temáticos que fez, não privilegiou a “Era Vargas”. Ele está em desvantagem, com certeza, mas não derrotado, uma vez que conseguirá responder à questão se mobilizar um dado fundamental da historicidade, que é a relatividade das opiniões. Outra questão: o professor terá como não privilegiar esse período? Ou continuamos diante de um rol de conteúdos que, embora não ditos assim, continuam sendo obrigatórios? Nesse sentido, até onde vai a liberdade de fazer os recortes temáticos? Que conhecimentos, que competências o aluno deverá ter para mobilizar na solução dessa questão? Percebamos que, apesar da indefinição de um conteúdo e da anunciada liberdade de selecioná-los conforme o entendimento do professor, o que se apresenta é a perspectiva de o ENEM acabar fazendo a se- 
leção de conteúdos que os PCNEM não fizeram, ou seja, de o Exame acabar ganhando um caráter de determinação dos conteúdos curriculares ao qual aparentemente os PCNEM teriam renunciado, resultando no que os "cursinhos" fazem hoje com a reserva de tempo de aula para cada assunto, conforme a freqüência em que tal ou qual assunto é cobrado nos vestibulares.

Seguindo outro rumo, suponhamos que seja possível responder a essa questão apenas com um conhecimento superficial sobre o tema. $\mathrm{O}$ aluno deverá mobilizar a competência de enfocar e avaliar a História diante de fontes que se contradizem, pois deverá ser capaz de desenvolver a noção de que são os sujeitos históricos que escrevem a História a partir de seu ponto de vista. Deverá ser capaz, também, de dimensionar o peso de cada um desses documentos para estabelecer um conhecimento sobre o período. Entretanto, esse dimensionamento será colocado pela questão apenas em termos de "certo" e "errado", prestando um desserviço a todo o trabalho que o professor tenha porventura feito de mostrar ao aluno a complexidade da produção das narrativas. A estrutura do exame não permitirá ao aluno expressar isso, pois constitui-se de alternativas fechadas que no fundo controlam os raciocínios: a prova não se interessa por eles, mas apenas pelo resultado "certo", que deve decorrer de um raciocínio "certo".

A questão seguinte, do ENEM de 1999, tem outros encaminhamentos para o conteúdo e exigências para o trabalho do aluno:

Em dezembro de 1998, um dos assuntos mais veiculados nos jornais era o que tratava da moeda única européia. Leia a notícia destacada abaixo:

O nascimento do Euro, a moeda única a ser adotada por onze países europeus a partir de $1^{\circ}$ de janeiro, é possivelmente a mais importante realização deste continente que nos últimos dez anos assistiu à derrubada do Muro de Berlim, à reunificação das Alemanhas, à libertação dos países da Cortina de Ferro e ao fim da União Soviética. Enquanto todos esses eventos têm a ver com a desmontagem de estruturas do passado, o Euro é uma ousada aposta no futuro e uma prova da vitalidade da sociedade Européia. A "Euroland", região abrangida por Alemanha, Áustria, Bélgica, Espanha, Finlândia, França, Holanda, Irlanda, Itália, Luxemburgo e Portugal, tem um PIB (Produto Interno Bruto) equivalente a quase $80 \%$ do americano, 289 milhões de consumidores e responde por cerca de $20 \%$ do comércio internacional. Com este cacife, o Euro vai disputar com o dólar a condição de moeda hegemônica. 
A matéria refere-se à "desmontagem das estruturas do passado" que pode ser entendida como

(A) O fim da Guerra Fria, período de inquietação mundial que dividiu o mundo em dois blocos ideológicos opostos.

(B) A inserção de alguns países do Leste Europeu em organismos supranacionais, com o intuito de exercer o controle ideológico no mundo.

(C) A crise do capitalismo, do liberalismo e da democracia levando à polarização ideológica da antiga URSS.

(D) A confrontação dos modelos socialista e capitalista para deter o processo de unificação das duas Alemanhas.

(E) A prosperidade das economias capitalista e socialista, com o conseqüente fim da Guerra Fria entre EUA e a URSS.

A questão exige como competência central a de interpretar o texto; subsidiária, mas imperativamente, o aluno tem que possuir uma interpretação sobre a Guerra Fria. Diferentemente da questão anterior, esta não pode ser respondida contando apenas com habilidades gerais que são desenvolvidas no estudo da História. Voltamos à problemática anterior: os recortes temáticos não são livres, obedecem a uma pauta de assuntos que não é explícita, mas está sendo agendada pelo ENEM e pelos vestibulares ainda. $\mathrm{O}$ ensino da História no Ensino Médio não pode se dedicar plenamente à formação da capacidade de pensar historicamente, pois deverá também vencer essa pauta de conteúdos. Depois de uma longa viagem, voltamos ao mesmo ponto: quem, quando, como, por que, para que e para quem os conteúdos são definidos? Apesar dos avanços da prova, não se pode afirmar ingenuamente que os conteúdos passaram à condição de meio, e não de fim, e apenas aparentemente as competências tomaram o lugar dos conteúdos na fila do que será cobrado do aprendiz das Ciências Humanas no Ensino Médio. A análise do recorte cronológico das questões é um indicativo disso, mas uma breve reflexão sobre os recortes temáticos pode ajudar a ir um pouco além nesse raciocínio.

\section{DESAFIOS DA RECOMPOSIÇÃO DIDÁTICA DOS CONTEÚDOS \\ DE HISTÓRIA E CARACTERÍSTICAS DO PROFISSIONAL}

O professor comprometido com a formação de sujeitos da transformação social, com um pouco mais de liberdade (por exemplo, a de cobrar a coe- 
rência com o que reza o texto oficial quando questionado sobre o que o seu trabalho tem a ver com História), continuará tendo que burlar as forças que produzem os sentidos para a educação e o querem reproduzir como executor do que é pensado no "andar de cima". Os PCN realizaram um fato que tem duas implicações: por um lado, eles "pasteurizam” as bandeiras da massa crítica que questionou e mudou o ensino de História ao longo dos anos 80 e início dos anos 90; por outro, ao absorver os seus cânones como discurso oficial, abrem um sustentáculo para que se continue enfrentando as resistências às transformações neste sentido.

O professor deverá equilibrar-se, mais ou menos como hoje, entre a necessidade de construir coletivamente os sujeitos com a habilidade de pensar o mundo e transformá-lo a partir dos instrumentais da História e das demais Ciências Humanas, e a contingência pragmática de ensinar os conteúdos que são exigidos pelos exames, entre formar o cidadão e treinar o estudante para ser aprovado em concursos.

Esse mesmo professor tem diante de si, entretanto, a possibilidade de ser sujeito - até certo ponto — dos seus conteúdos e materiais. Dificilmente os livros didáticos como conhecimento hoje poderão dar conta dos objetivos propostos para o ensino médio, e a relação de dependência em relação a livros e apostilas fica reduzida em importância, pois mais que seguir enciclopedicamente uma seqüência, cabe definir rumos próprios de realização de um trabalho cujo objetivo não é acumular, mas propiciar experiências de crescimento qualitativo do pensamento.

Apesar do tom predominantemente negativo deste texto, não se pode deixar de reconhecer os PCN como um avanço em relação a currículos nacionais anteriores, ressaltando principalmente a vitória sobre a lógica da cronologia como princípio estruturador dos conteúdos da história. Não se deve esquecer, entretanto, que os PCN, com sua voracidade unificadora, passam por cima de dezenas de experiências curriculares regionais positivas, ainda que se beneficiando de seus ganhos.

Pode-se optar pela tendência "panglossiana" ${ }^{14}$ de que não estamos no melhor dos mundos, mas no melhor dos mundos possíveis, com seu conformismo em relação ao presente, ou pode-se optar por uma tendência a compreender quais seriam os mundos possíveis, na recusa a simplesmente adaptar os alunos ao mundo atual, treinando-os para a integração na "história terminada". Burlar os PCN é apontar para os alunos a existência de diversos mundos possíveis, mostrar que a História não é a explicação de como esses mundos foram recusados para que tivéssemos apenas o mundo que temos, 
mas a explicação de que escolhas foram feitas para que chegássemos à forma atual do presente, e que outras escolhas podem ser feitas, se pudermos olhar para além da medíocre e decepcionante "utopia do possível".

Nos PCN, os conteúdos apenas são móveis, e mesmo assim de forma controlada, como já afirmamos. Os objetivos, a teoria e a metodologia vêm travados, definidos. Burlar os PCN é desmontar esse mecanismo, rejeitando a etiqueta que diz que "aqui não há peças passíveis de ajuste pelo usuário, procure um serviço autorizado”, e destravar objetivos, teoria e metodologia. Não se contentar com a liberdade de seleção dos conteúdos. Discutir aquilo que é decretado como consenso.

\section{NOTAS}

${ }^{1}$ A primeira versão deste texto foi apresentada em mesa redonda do evento "PCN em sala de aula: que história é essa”, promovido pelo GT de Ensino de História da Educação da Anpuh-PR e pelo Colégio Positivo, em fevereiro de 2002. Para a atualização do texto com as novas questões do ENEM, contei com ajuda dos alunos do Plano de Acompanhamento de Estudos em Oficina de Ensino de História da UEPG.

${ }^{2}$ BUENO, M. S. S. Orientações nacionais para a reforma do ensino médio: dogma e liturgia. In: Cadernos de Pesquisa, n.109, p.7-23, mar.2000, p.9.

${ }^{3}$ SOARES, M. A. N. O ensino de História presente nos Parâmetros Curriculares do Ensino Médio (PCNEM): A construção do sujeito adequado. História \& Ensino. Londrina, PR, v.8, p.29-44, out 2002.

${ }^{4}$ GIROUX, H. Os professores como intelectuais. Porto Alegre: Artes Médicas, 1997.

5 "Os meios de comunicação social que constituem um dos mecanismos mais representativos do intercâmbio comunicacional entre as classes, do modo como funcionam atualmente, em geral agem de forma destrutiva, no sentido da 'desconfirmação positiva': mesmo que seus conteúdos pareçam amáveis e comedidos, informativos e divertidos, a outra dimensão de sua mensagem total 'desconfirma' a maioria da população, ignorando as pessoas e tratando de 'massificar' ou despersonalizar". TERRERO, J. M. Comunicação grupal libertadora. São Paulo: Paulinas, 1988, p.18.

${ }^{6}$ GIROUX, H. apud SILVA, M. H. G. F. D. da. O professor e seu desenvolvimento profissional: superando a concepção do algoz incompetente. Caderno do CEDES. Campinas, SP, v.XIX, n.44, p.33-58, abr.1998, p.37.

${ }^{7}$ Ver, a esse respeito, o editorial de Paulo Eduardo Dias de Mello, "Pedagogia da Inclusão", para o jornal Bolando Aula de História. Santos, SP, n.22, maio.2000. 
${ }^{8}$ Esta abordagem de Foucault vem com o filtro de CANIVEZ, P. Educar o cidadão. Ensaios e textos. Campinas, SP: Papirus, 1991, p.45-52.

${ }^{9}$ Cf. CHAUÍ, M. Cultura e Democracia: o discurso competente e outras falas. 5.ed. São Paulo: Cortez, 1990, p.28.

${ }^{10}$ SYLVESTER, D. Change and continuity in history teaching. 1900-93. In: BOURDILLON, H. Teaching History. London, New York: Open University, 1996, p.18.

${ }^{11}$ Ver, entre outros, KUENZER, A. Z. Conhecimento e competências no trabalho e na escola. Caxambu, MG: 25를 Reunião Anual da ANPED, 2002. Disponível em www.anped.org.br/25/sessoesespeciais/ acaciazeneidakuenzer.doc, acessado em 9.maio.2003. ${ }^{12}$ Apesar de, a partir de 2003 o ENEM ser realizado sob a orientação do governo Lula, trata-se de mais um dos casos em que o programa criado no governo anterior recebe continuidade sem uma rediscussão crítica.

${ }^{13}$ FUNARI, P. P. A importância de uma abordagem crítica da História Antiga nos livros escolares. Disponível em www.nethistoria.com/index.php?pagina=ver_texto\&titulo_id=186, acessado em 27.ago.2004.

${ }^{14}$ Ver o Cândido, de Voltaire. 